\title{
Regolith Activation on the Lunar Surface and Its Ground Test Simulation
}

James R. Gaier

Glenn Research Center, Cleveland, Ohio 


\section{NASA STI Program . . . in Profile}

Since its founding, NASA has been dedicated to the advancement of aeronautics and space science. The NASA Scientific and Technical Information (STI) program plays a key part in helping NASA maintain this important role.

The NASA STI Program operates under the auspices of the Agency Chief Information Officer. It collects, organizes, provides for archiving, and disseminates NASA's STI. The NASA STI program provides access to the NASA Aeronautics and Space Database and its public interface, the NASA Technical Reports Server, thus providing one of the largest collections of aeronautical and space science STI in the world. Results are published in both non-NASA channels and by NASA in the NASA STI Report Series, which includes the following report types:

- TECHNICAL PUBLICATION. Reports of completed research or a major significant phase of research that present the results of NASA programs and include extensive data or theoretical analysis. Includes compilations of significant scientific and technical data and information deemed to be of continuing reference value. NASA counterpart of peer-reviewed formal professional papers but has less stringent limitations on manuscript length and extent of graphic presentations.

- TECHNICAL MEMORANDUM. Scientific and technical findings that are preliminary or of specialized interest, e.g., quick release reports, working papers, and bibliographies that contain minimal annotation. Does not contain extensive analysis.

- CONTRACTOR REPORT. Scientific and technical findings by NASA-sponsored contractors and grantees.
- CONFERENCE PUBLICATION. Collected papers from scientific and technical conferences, symposia, seminars, or other meetings sponsored or cosponsored by NASA.

- SPECIAL PUBLICATION. Scientific, technical, or historical information from NASA programs, projects, and missions, often concerned with subjects having substantial public interest.

- TECHNICAL TRANSLATION. Englishlanguage translations of foreign scientific and technical material pertinent to NASA's mission.

Specialized services also include creating custom thesauri, building customized databases, organizing and publishing research results.

For more information about the NASA STI program, see the following:

- Access the NASA STI program home page at http://www.sti.nasa.gov

- E-mail your question via the Internet to help@ sti.nasa.gov

- Fax your question to the NASA STI Help Desk at 443-757-5803

- Telephone the NASA STI Help Desk at 443-757-5802

- Write to: NASA Center for AeroSpace Information (CASI) 7115 Standard Drive Hanover, MD 21076-1320 


\section{Regolith Activation on the Lunar Surface and Its Ground Test Simulation}

James R. Gaier

Glenn Research Center, Cleveland, Ohio

Prepared for the

39th International Conference on Environmental Systems (ICES)

sponsored by the Society of Automotive Engineers International

Savannah, Georgia, July 12-16, 2009

National Aeronautics and

Space Administration

Glenn Research Center

Cleveland, Ohio 44135 
Trade names and trademarks are used in this report for identification only. Their usage does not constitute an official endorsement, either expressed or implied, by the National Aeronautics and Space Administration.

Level of Review: This material has been technically reviewed by technical management.

Available from

NASA Center for Aerospace Information 7115 Standard Drive

Hanover, MD 21076-1320
National Technical Information Service 5285 Port Royal Road Springfield, VA 22161

Available electronically at http://gltrs.grc.nasa.gov 


\title{
Regolith Activation on the Lunar Surface and Its Ground Test Simulation
}

\author{
James R. Gaier \\ National Aeronautics and Space Administration \\ Glenn Research Center \\ Cleveland, Ohio 44135
}

\begin{abstract}
Activation of the surfaces of lunar regolith particles can occur through interactions with solar electromagnetic radiation, solar and galactic particle radiation and micrometeoroid bombardment. An attempt has been made to quantify the relative importance of each of those effects. The effects of these activated surfaces may be to enhance the adhesion and toxicity of the particles. Also key to the importance of activation is the lifetimes of activated states in various environments which is controlled by their passivation rate as well as their activation rate. Although techniques exist to characterize the extent of activation of particles in biological system, it is important to be able to quantify the activation state on the lunar surface, in ground-test vacuum systems, and in habitat atmospheres as well.
\end{abstract}

\section{Introduction}

The surface of the Moon is covered by a layer of crushed rock from 8 to $48 \mathrm{~m}$ deep known as the lunar regolith (Ref. 1). The composition of the regolith samples returned from the six Apollo sites and the two Luna sites have been studied in great detail. These are summarized in the Lunar Sourcebook, (Ref. 2) and numerous other references. From these studies it is known that 65 to 90 percent of the regolith is composed of silicate minerals, depending on location on the lunar surface. The largest component is made of plagioclase feldspars [(Ca$\mathrm{Na})(\mathrm{AlSi})_{4} \mathrm{O}_{8}$ ], followed by pyroxenes [(Ca-Fe-Mg) $\left.\mathrm{Si}_{12} \mathrm{O}_{6}\right]$ and then olivine [(Mg-Fe $\left.)_{2} \mathrm{SiO}_{4}\right]$. Oxide minerals such as ilmenite $\left[(\mathrm{Mg}-\mathrm{Fe}) \mathrm{TiO}_{3}\right]$ and spinels $\left[\mathrm{FeCr}_{2} \mathrm{O}_{4}, \mathrm{FeTiO}_{4}, \mathrm{FeAl}_{2} \mathrm{O}_{4}\right.$, $\mathrm{MgTiO}_{4}$ ] are present as well. Although the spinels occur in only trace amounts, they are extremely hard and may be important abrasive agents. Ilmenite, which can act as an oxygen ore, has been found in mare basalts in concentrations as high as 20 percent, but only about 0.5 percent in the highlands. Volcanic and impact glasses can make up from about 7 to 30 percent of the regolith. In addition there are small amounts of native metals $\left[\mathrm{Fe}^{0}, \mathrm{Ni}^{0}, \mathrm{Co}^{0}\right]$; phosphate minerals, primarily whitlockite $\left(\mathrm{Ca}_{3}\left(\mathrm{PO}_{4}\right)_{2}\right)$; and sulfur, primarily in the form of troilite $[\mathrm{FeS}]$. Some soils contain small amounts of material high in potassium (generally much less abundant on the Moon than on Earth), rare Earth elements, and phosphorus referred to as KREEP. In addition there are about 100 other minerals present in trace amounts, some of which have not been observed terrestrially.

It is thought that the lunar regolith is formed by a series of highly energetic processes known as space weathering.
Energetic solar particles and galactic cosmic rays constantly bombard the lunar surface. This results in the implantation of atoms, primarily hydrogen and helium, as well as sputtering of atoms off of surface of particles. Meteoroids continually strike the surface as well. Even though the vast majority of these are tiny $(<1 \mathrm{~mm})$ they strike the surface with so much kinetic energy that they both break up rock and melt it. A series of complex processes follows from this that includes the release of adsorbed and implanted hydrogen and helium, the release of oxygen from the rock structure, the reduction, vaporization and redeposition of iron, and the flow of molten rock downward to form agglutinates and impact breccias.

\section{Regolith Activation}

One of the results of these energetic processes is that a relatively large number of highly reactive surface atoms are thought to be formed. Such surfaces are said to be "activated". Activation includes any process that enhances the chemical reactivity of the surface. Activated states can result from three basic mechanisms. The first is the ejection of electrons from the surface by light in the ultraviolet or $\mathrm{x}$-ray regions (0.01 to $300 \mathrm{~nm}$ wavelengths) resulting in free radicals, that is, atoms with unpaired electrons. These are usually chemically unstable and will react with the first atomic collision after they are formed. The second is the sputtering of atoms off of the surface, which often results in the remaining surface atoms having "dangling bonds", or unsatisfied valence shell electrons. These are also chemically reactive. Third, high energy collisions with micrometeorites or energetic particles ejected from the Sun can result in crystal lattice defects, with atomic displacements which can lead to highly strained structures. These highly strained structures are also chemically very reactive.

Passivation is the process of relaxation of atoms back to the ground state. These processes are dominated by collisions with low energy atoms, but also include spontaneous emission of light, or radiationless relaxation processes. Because of the ultrahigh vacuum present on the Moon, $10^{-12}$ Torr during the day and $10^{-14}$ Torr during the night, there are few collisions with gas phase atoms to relax or passivate these states. Thus, it is expected that the concentration of these activated states can become significant.

The presence of activated surface states may materially change some of the properties of regolith particles. This is expected to be most significant for the smallest particles (i.e., dust), since they will have the highest surface to volume ratios. Adhesion of the dust to other materials, including spacecraft 
components, is expected to increase as the probability of forming covalent bonds from free radicals and dangling bonds is higher. This would make it more difficult to clean the dust from sensitive spacecraft surfaces. If the activated dust is brought into contact with the humid air of the cabin, it might accelerate corrosion or even might catalyze unwanted reactions of trace gases in the atmosphere. Finally, there is also a possibility that the toxicity of the dust could be dramatically increased, as happens terrestrially with silica (Ref. 3).

The technologically important question is not whether the dust is activated, but rather, if it is activated what are the consequences? For example, it is reasonable to assume that the adhesion forces between the regolith and a sensitive spacecraft surface (such as a radiator or a photovoltaic array) will increase since there will be more opportunity for chemical bond formation when one or both of those surfaces is chemically active, but will it change the performance of the surface or the techniques to clean it?

It is well known that adhesive forces may increase a hundredfold or more in ultrahigh vacuum due to clean body effects (Ref. 4). But it is not yet known whether activation will significantly increase the adhesion even more. But if it does and we understand the mechanisms by which the adhesion is enhanced, it may point the way to mitigation technologies. For example, cleaning off dust in an airlock that has been partially pressurized may be much more effective than cleaning in the hard vacuum of the Moon because a large fraction of the active sites may be passivated before the cleaning process begins.

If the effects of activated dust on spacecraft components and health are to be studied, techniques must be developed to measure the degree of activation, and to generate activated dust. But the detection and quantification of activated surfaces is not a trivial matter. Physical changes, such as the displacement of surface atoms and the imaging of defect sites can be done using atomic force microscopy (AFM), transmission electron microscopy (TEM), field effect transmission electron microscopy (FETEM), or electron diffraction. However, these techniques can also impart surface damage of their own, and it is difficult to unambiguously assign the cause to a particular defect. They are also time consuming and can only be done after the test is completed. What is needed is a diagnostic test that can be carried out in situ so that the activation state of the lunar regolith or lunar regolith simulant sample can be verified before it is used to test hardware components.

One test that has been proposed is the utilization of a quartz crystal microbalance (QCM). These instruments are very sensitive to mass changes. So if a surface is activated it will react with a reactive gas, such as oxygen, to a greater extent than a passivated surface would. Such an additional mass uptake may well be measurable using a QCM.

A novel technique to quantify the activation of lunar dust simulants has been explored by Vander Wal et al., who monitored the electrical conductivity of the dust as it was subjected to a discharge plasma in a vacuum chamber (Ref. 5).
Although much work remains to quantify this effect, it is relatively straightforward to implement within a vacuum chamber, and so holds promise as an in situ activation detector. One of the major obstacles is that a quantitative measure of the activation state of the dust on the lunar surface itself is unknown. This technique lends itself to an instrument that could be mounted on a lunar lander to determine the dynamic changes in activation state of dust on the lunar surface.

In all likelihood some fraction of dust will be tracked from the lunar surface into the lunar habitat and pressurized rover cabins. The activated surface of this dust can react with oxygen and water vapor to form hydroxyl $(\mathrm{OH})$ peroxyl radicals $(\mathrm{OOH})$. These are very reactive and corrosive agents that if present in the cabin atmosphere in high enough concentrations over long enough times can corrode metals and embrittle polymers.

Dust activation is also of intense interest to NASA's toxicology community due to the possibility that activation can significantly enhance the toxicity of lunar dust. In this case, the questions revolve around the passivation mechanisms in the humid air within the lung. If the dust is passivated in air quickly, then whether activation enhances the toxicity is less important than if the passivation times are long enough to affect human exposure. If the species persists long enough to be transported into the lung, then as they passivate they may generate reactive oxygen species such as hydroxyl and peroxyl radicals in high enough concentrations to overwhelm the body's defenses and damage biological tissues.

Wallace and co-workers have developed procedures and analytical tests to quantify activation under biological conditions (Ref. 6). The tests rely on the activated surfaces generating reactive hydroxyl radicals, which are then assayed with a fluorescent probe. This is a particularly relevant test as it is these secondary products like hydroxyl and peroxyl radicals that do the most damage to biological systems.

\section{Evidence For Regolith Activation}

There is experimental evidence that the lunar regolith exists on the lunar surface in an activated state. For example, Hoyt, et al., were able to reconstruct the solar flare proton spectrum over the past 5000 yr by studying the thermoluminescence caused by radiation damage (Ref. 7). They found radiation damage (lattice dislocations) in the top $18 \mathrm{~mm}$ of lunar rock, decreasing towards the bottom. Most of the damage was attributable to solar flare protons. Cosmic ray damage was found even deeper within the rocks.

In another example, Grossman, et al., measured the cohesion in a porous friable microbreccia in Apollo 11 sample 10065-33 in a vacuum of $7 \times 10^{-10}$ Torr (Ref. 8). Upon cleaving the sample the cohesion between the two pieces was measured to be $8 \times 10^{-3} \mathrm{~N}$. After just $4 \mathrm{~min}$ the cohesion dropped to $2 \times 10^{-3} \mathrm{~N}$, and within 15 min the forces were too weak to be measurable. This may be due to quenching of activated sites by gas 
molecules. Although tested at $10^{-10}$ Torr, the pressure is still two to four orders of magnitude higher than lunar pressures.

Further evidence of regolith activation comes from the experience of the Apollo astronauts. Several of them remarked that when they first took their helmets off after being on the lunar surface that the lunar dust had a pungent odor, often described as the smell of burnt gunpowder. This smell can be the result of olfactory cells responding to free radicals, such as $\mathrm{NO}_{\mathrm{x}}$ (a stable free radical) which has a pungent odor as well. Further, the lunar curator reported at the Biological Effects of Lunar Dust Workshop in 2005 that "the gunpowder smell went away in a few hours (Ref. 9).” This would be consistent with the passivation of free radicals on the particle surfaces.

\section{Lunar Simulants}

In order to simulate the effects of the particle surface activation four conditions must be met. First, the particles being activated must have the correct bulk composition and chemistry. Starting with materials that have a different elemental composition, or even with materials with the same composition but a different crystal form will not lead to the same surface chemistry. Second, activation mechanisms must be used that will produce the same types of surface damage or modification. This does not imply that the activation must be done using the same mechanism. An atom that is a free radical or has dangling bonds or is in a strained lattice position will react the same regardless of how that excited state is formed. Third, the passivation mechanisms must be slow enough that the activated dust has time to react with whatever other substances or surfaces. Particles activated in air, for example, are likely to react with the surrounding atmosphere long before reaching the substance of interest, given that there are about 30 million collisions per second for a gas at atmospheric pressure (Fig. 1). Last, there must be some way to detect the presence of activated surface species, so that effects seen can be rightly attributed.

Due to the paucity of lunar material available on Earth, most work will necessarily be carried out using lunar simulants. There are several lunar simulants that are available, and more are being developed. Probably the most used simulant at the time of writing is JSC-1A, which mimics lunar mare regolith, and the most prominent in development in NU-LHT, which mimics lunar highlands regolith.

Lunar simulants are made from terrestrial rock and minerals, and some common components of terrestrial rock are rare or absent in lunar materials. Potassium feldspars [(K-Al) $\left.\mathrm{Si}_{3} \mathrm{O}_{8}\right]$ and silica $\left[\mathrm{SiO}_{2}\right]$ though abundant in terrestrial rock, are rare in the lunar samples. Absent on the Moon (at least in the equatorial regions) because they contain water are micas, clays, and amphiboles. These minerals should likewise be absent from lunar simulants. In addition, the simulant should have a substantial glassy fraction, since much of the lunar regolith is dominated by glasses produced during space weathering. This is important because displacement of surface atoms in a

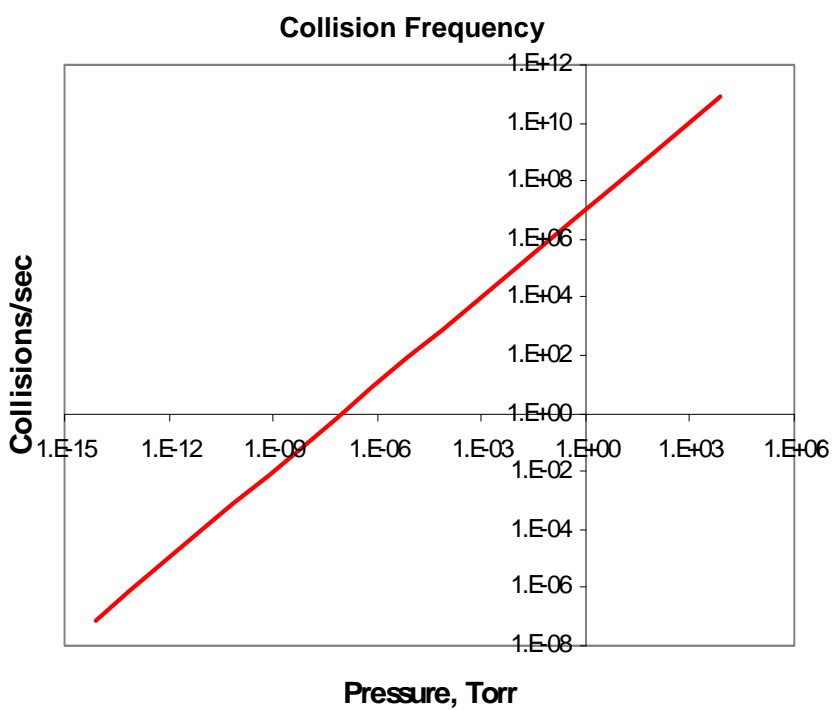

Figure 1.-Collision frequency calculated for $\mathrm{N}_{2}$ molecules at $298 \mathrm{~K}$ as a function of pressure from kinetic molecular theory (Ref. 10). Other molecules in the lunar temperature range give similar values.

highly ordered crystal lattice is a higher energy process than displacement of surface atoms in a glass. For example, if an oxygen atom in a disordered glass structure is bound to a single silicon atom instead of two, calculations show that the energy to remove it from the lattice is decreased by about $5 \mathrm{eV}$ (Ref. 11).

The surface properties of lunar simulant under terrestrial conditions will not mimic the surface properties of lunar regolith under lunar conditions. In fact, lunar regolith will not react the same under terrestrial conditions as it will under lunar conditions. The environment of the Earth is humid, oxidizing and protected from high energy radiation by the Earth's magnetic field and atmosphere. In contrast, the lunar environment is dry, chemically reducing, and constantly bombarded by high energy electromagnetic and particle radiation. The surface chemistry of any material will be different in these two environments.

The first step in any process to produce activated lunar simulant would be to remove the adsorbed layer of Earth atmospheric gases from the surface of the particles. Such studies are being carried out in the Lunar Dust Adhesion Bell Jar (LDAB). This is a facility built to determine the effects of the lunar environment on adhesion to sensitive spacecraft surfaces. Details of its philosophy and design have been reported elsewhere (Ref. 12). By far the largest contaminant is water vapor, which is almost totally absent from the lunar environment. Studies suggest that heating the simulant in vacuo or even in an atmosphere of dry nitrogen to a temperature of $200{ }^{\circ} \mathrm{C}$ can accomplish this (Ref. 13). There is an additional problem with water in that most terrestrial rock have inclusions that contain water between the crystalline grains deep within the rock. This may take very high temperatures to remove, but removing it may not be necessary if diffusion of this reservoir of water to the surface is sufficiently slow. 
The second largest contaminant is likely organic molecules such as methane, ethane, and hydrocarbon oils that are nearly ubiquitous in the Earth's environment. It is easiest to remove these organics through oxidation. There are many routes to oxidation, but using a gas phase method that will not distort the surface composition of the rock is probably best. Either oxygen plasma (as is used in the LDAB) or ozone generation can result in reactive oxygen that can convert hydrocarbons to volatile carbon dioxide. Since the dominate minerals are aluminosilicates, silicates, and oxides, the surface composition will likely be unchanged.

The oxidation processes described above will leave the surface highly oxidized. This means that transition metals such as iron will likely be in very high oxidation states, such as iron (III). The lunar surface, on the other hand, is being bombarded by a constant stream of hydrogen and helium atoms and ions from the solar wind, which generate a highly reduced surface. Iron (III) is almost unknown on the lunar surface, with the iron being predominantly in the iron (II) state, or even in the iron (0) state. So this preponderance of water and oxygen that is found adsorbed to the surface of terrestrial materials must replaced with a preponderance of hydrogen.

After a correct bulk material has been obtained, the terrestrial surface layer stripped off, and lunar-like surface layer has been added, then the simulant can be activated. There are many ways this can be accomplished. In the LDAB the dust is subjected to a second plasma, where the gas is a 6 percent hydrogen in helium mixture. Although the solar wind is about 96 percent protons and 4 percent $\alpha$ particles, the much higher helium content was selected for safety reasons. It has also found that the sticking coefficient of hydrogen is so much higher than helium that hydrogen dominates the surface adsorption despite its lower concentration. Whenever the dust is stirred, sifted, or crushed in the LDAB, hydrogen is released but helium is not.

\section{Mechanisms of Activation}

As illustrated in Table I, typical mineral bonds have strengths that range from 3 to $9 \mathrm{eV}$ (Ref. 14). Thus any mechanism that can impart more than about $3 \mathrm{eV}$ to a surface atom has the potential to activate it.

\section{TABLE I.-ENERGY OF OXIDES FOUND IN LUNAR REGOLITH ${ }^{\dagger}$}

\begin{tabular}{|l|c|c|c|c|c|}
\hline \multicolumn{1}{|c|}{$\mathrm{eV}$} & $\Delta \mathrm{H}_{\text {bond }}$ & $\Delta \mathrm{H}_{\text {form }}$ & $\Delta \mathrm{H}_{\text {lattice }}$ & $\Delta \mathrm{H}_{\text {sublimation }}$ & $\Delta \mathrm{H}_{\text {ionization }}$ \\
\hline $\mathrm{SiO}_{2}$ & 8.15 & -9.44 & 136 & 4.66 & 45.1 \\
$\mathrm{TiO}_{2}$ & 7.28 & -9.79 & 126 & 4.90 & 43.3 \\
$\mathrm{Al}_{2} \mathrm{O}_{3}$ & 4.98 & -17.4 & 165 & 3.42 & 28.5 \\
$\mathrm{CaO}$ & 4.77 & -6.58 & 35.4 & 1.84 & 11.9 \\
$\mathrm{Cr}_{2} \mathrm{O}_{3}$ & 4.37 & -11.8 & 158 & 4.11 & 31.0 \\
$\mathrm{MgO}$ & 3.90 & -8.20 & 39.3 & 1.52 & 15.0 \\
$\mathrm{Na}_{2} \mathrm{O}$ & 3.34 & -4.29 & 25.7 & 1.11 & 5.14 \\
$\mathrm{FeO}$ & 1.60 & -2.82 & 39.3 & 4.32 & 16.2 \\
\hline
\end{tabular}

\footnotetext{
${ }^{\dagger}$ Although the metals are largely bound to oxygen in the mineral crystal lattices, and traditionally expressed as oxides as in this table, it is not correct to think of the minerals as being a simple collection of metal oxides, as their structure is much more complex.
}

One potential energy source is the light energy emitted by the Sun. The Sun is a much more potent source of ultraviolet radiation on the Moon than the Earth because a substantial portion of the solar electromagnetic output is filtered out by the atmosphere of Earth, much of it by the ozone layer. A plot of the standard "air mass zero" is shown in Figure 2 (Ref. 15). This is the spectrum observed just above the Earth's atmosphere, and is what is seen on the lunar surface as well. Note that the bulk of the radiation is in the visible and infrared regions of the spectrum, between about 0.2 and $7 \mathrm{eV}$.

Work by Sternovsky et al., found that the work function (energy to extract an electron from the surface) of the lunar regolith can be expected to be about $5.8 \mathrm{eV}$ (Ref. 16). Analysis of the spectrum of the solar energy reaching the lunar surface reveals that about 0.1 percent of the energy released by the Sun is in the form of photons that have energy greater than $5.8 \mathrm{eV}$ (wavelength $<213 \mathrm{~nm}$ ), enough energy to remove an electron and form a free radical. Given that the intensity of the solar flux is $1366 \mathrm{~W} / \mathrm{m}^{2}$, on average each surface atom will be hit by a photon with more than $5.8 \mathrm{eV}$ of energy about once every 2 min.

In the LDAB there are two processes that generate UV light with more than $5.8 \mathrm{eV}$. The first is through two radio frequency plasmas used to prepare the dust. The first plasma is an air plasma used to oxidize away organic matter contaminating the dust. The second plasma is a hydrogen-helium plasma used to chemically reduce the surface states. Analysis of the emission spectrum reveals that about 1 percent of the light given off has an energy greater than $5.8 \mathrm{eV}$. Each plasma has an input power of $200 \mathrm{~W}$ applied for $1 \mathrm{hr}$, or a total of $720 \mathrm{~kJ}$. However, it is not known how the energy is partitioned between ionization and excitation of electronic states, or what fraction of the light impinges on the dust, so the flux cannot be calculated.

The second UV generating process is through heating the dust coated samples with a Xe arc lamp. The intensity of the LDAB arc lamp is about 20 Suns, so following from the

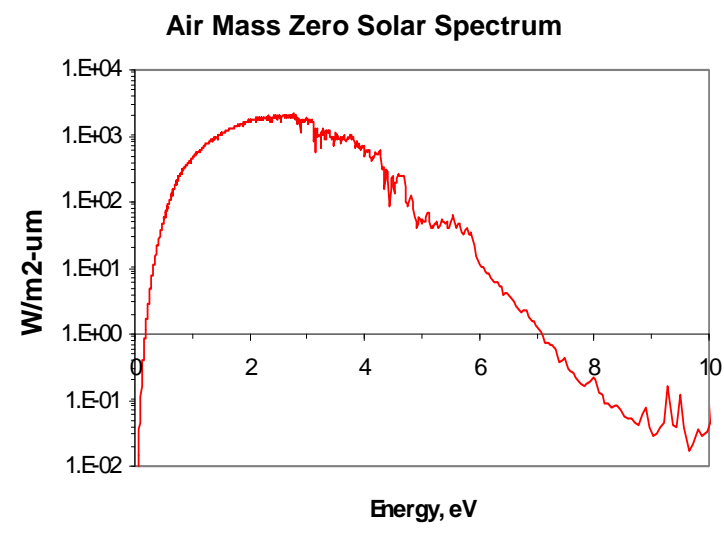

Figure 2.-Air mass zero solar spectrum over its most intense energy region (Ref. 13). 
estimation above, each atom should be exposed to a phonon with $5.7 \mathrm{eV}$ energy or higher about every 6 sec. It should be noted that the dust is only exposed to that flux for about $15 \mathrm{~min}$ during the test.

In addition to electromagnetic radiation, the Sun also bombards the lunar surface with high energy particles, largely protons, but $\alpha$ particles as well. By far the greatest number of these come from the solar wind, but solar storms and solar flares bombard the surface with less frequent, but higher energy particles. In addition, the lunar surface is also bathed in a low flux of very high energy cosmic rays.

Figure 3, adapted from Wilson, et al., shows the particle radiation flux density and energy emitted by the Sun to the Moon (Ref. 17). A typical mineral crystal will have about $10^{15}$ atoms $/ \mathrm{cm}^{2}$ of surface. Extrapolation of the solar wind protons to that value leads to the conclusion that a solar wind proton will strike a surface atom carrying a $\mathrm{keV}$ or more of energy each $(24 \mathrm{hr})$ day. Similarly, it will interact with a 1 $\mathrm{MeV}$ solar storm proton about once per millennia, a $100 \mathrm{MeV}$ proton, and a $\mathrm{GeV}$ cosmic ray about once every 100 million years. These energetic particles may have several collisions within the lattice before they come to rest, and will often become implanted, as evidenced by their release as hydrogen gas from the Apollo samples (Ref. 18). They also sputter atoms from the surfaces of the particle, resulting in dangling bonds and lattice dislocations.

High energy particle radiation is simulated in the LDAB by the radio frequency plasmas described previously. Again, it is difficult to know how the total energy is partitioned between electromagnetic radiation and the ion formation and accelerations. Further, it is not known what fraction of the ions strike the dust, nor with what energy. An in situ instrument that could quantify the extent of activation would be useful in determining how long the dust should be exposed to the plasma.

The meteoroid flux that the International Space Station is exposed to has been quantified by Christiansen (Ref. 19). A log-linear extrapolation of his Figure 1-2 to smaller particles sizes shown in Figure 4 has been used to estimate the micrometeoroid flux on the lunar surface.

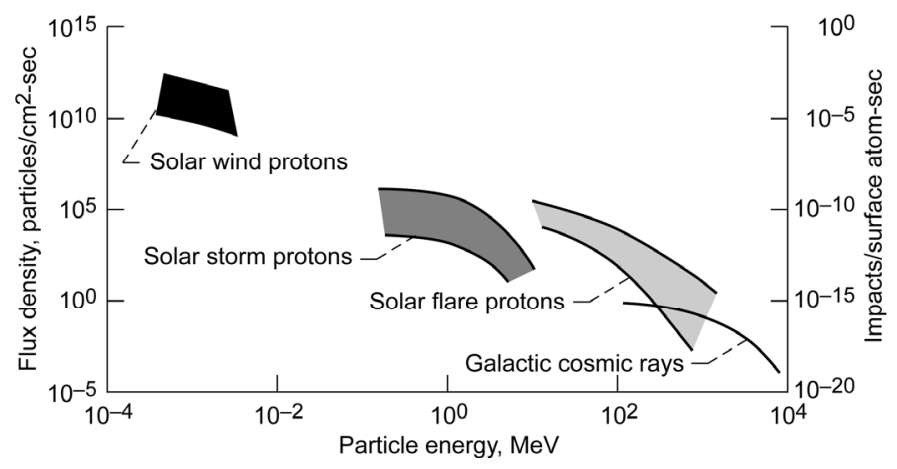

Figure 3.- Impacts per lunar surface atom per second for energetic radiation. (Adapted from Wilson, et al. (Ref. 3).)

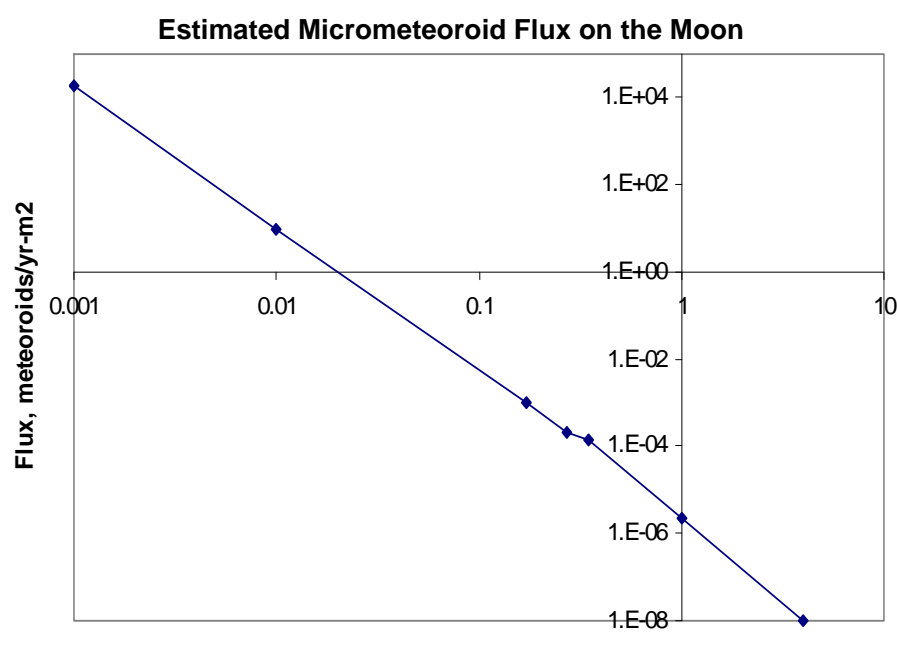

Particles size, $\mathbf{c m}$
Figure 4.--Impacts on lunar surface per year per $\mathrm{m}^{2}$. (Adapted from Christiansen (Ref. 16).)

It is assumed that the flux in low Earth orbit is similar to that of the lunar surface. It is recognized that because of the greater size of Earth's gravity well, the flux on the lunar surface is probably somewhat lower. The estimate is that each year there will be about ten $100-\mu \mathrm{m}$ meteoroids and about ten thousand $10-\mu \mathrm{m}$ meteoroids strike each square meter of surface.

Each of these high energy collisions with the regolith will result in the fracture of a large number of particles. The surfaces of freshly ground minerals are characterized by the presence of highly reactive free radicals (Ref. 3), and since the regolith was formed by impact fracture, they probably form on the lunar surface as well. These fracture surfaces often include "shock structures" which include dislocations and dangling bonds which will be chemically active. Thermal excursions which can be as large as $300 \mathrm{~K}$ near the equator will induce thermal stresses which may create new dislocations and fracture surfaces.

Micrometeor impacts can be simulated by fracturing the simulant using high impact milling. As the grains fracture, defect sites will be present that are induced by the strain before fracture. Although this method may be used to activate dust or test of reactivity in the habitat or toxicological environment, it would be difficult to generate this type of activation in a vacuum environment. That being said, Grossman et al.'s study referred to above induced a single fracture of a relatively large rock to study the nature of fracture activation (Ref. 7).

\section{Mechanisms of Passivation}

While there are many processes on the lunar surface to activate particle surfaces, there are not many passivation mechanisms. Under the rarified atmosphere (actually a ballistic exosphere) with pressures of $10^{-12}$ Torr on the day side and $10^{-14}$ Torr on the night side, there are very few collisions with gaseous atoms that have a chance to relax the active site. Such atoms as do collide will have such low collisional energy that 
few will be able to heal a lattice defect, as is illustrated in Hoyt's study referred to above (Ref. 6). As a result, passivation in the lunar environment is expected to be a very slow process.

The work to produce the highly activated surfaces in ground test systems will be for naught if passivation occurs before the active surface can react with the experimental surface in question. One possibility is auto-passivation, that is energy can be emitted to return an excited atom to the ground state, or a lattice defect may spontaneously correct itself. But more often passivation will be the result of collisions with other atoms. So the most effective way to limit passivation is to limit the exposure of the activated material to external atomic collisions. Figure 1 shows a plot of molecular collisions/sec as a function of pressure. Examination of the collision frequency reveals that effectively, this means by operating in a vacuum.

Each type of activation site will have its own passivation energy. Free radicals have such a low passivation energy that they are usually passivated by the first collision, whereas that of lattice defects is so high that they can be used to track solar activity over thousands of years (Ref. 3). The probability that a collision will be by an atom or molecule with sufficient energy is provided by the Boltzmann distribution, which is very sensitive to temperature. So the best condition to extend the lifetime of the activated stated is low pressure and low temperature.

The LDAB tests are carried out in a vacuum of $10^{-8}$ Torr. At these pressures the passivation of the particle surfaces will be slowed, but the pressure is still 10,000 times higher than even the dayside pressure on the Moon. Tests must be carried out in UHV facilities at $10^{-12}$ Torr to determine how these passivation rates compare with those at lunar pressures.

\section{Conclusions}

The lunar surface is an energetic environment. Electromagnetic and particle radiations emanating from the Sun contain a small fraction of photons and protons that are energetic enough to create free radicals, dangling bonds, and lattice defects. There is circumstantial evidence from the Apollo record that these activation processes do occur. These high energy activation sites can affect the reactivity of the dust particle surface enough to affect their adhesion to spacecraft surfaces and human toxicology.

Avenues are being explored to generate activated dust surfaces using mechanical, thermal, and chemical means. Progress is being made on the quantification of the activation state under high vacuum conditions. Methods to quantify their potential for toxicological effects are already well known.

It is important to quantity the passivation rates in a variety of environments. Since they are dependent on molecular collisions they will vary widely depending on whether their environment of interest is the lunar surface, standard ground-test vacuum systems, airlocks, habitats, or within the lung. Overall it is important to understand all aspects of activated states on dust particles; how they are formed, how the effect mechanical and biological systems, and how they are passivated.

\section{References}

1. B.B. Wilcox, et al., "Constraints on the Depth and Variability of the Lunar Regolith,” Meteoritics \& Planetary Science, 40(5) (2005) pp. 695-710.

2. G.H. Heiken, D.T. Vaniman, and B.M. French, The Lunar Sourcebook: A User's Guide to the Moon, (Cambridge University Press, 1991).

3. B. Fubini, E. Giamello, M. Volante, V. Bolis, "Chemical functionalities at the silica surface determining its reactivity when inhaled. Formation and reactivity of surface radicals,” Toxicology and Industrial Health 6 (1990) pp. 571-598.

4. J.J. Grossman and J.A. Ryan, "Comments on Lunar Surface Adhesion,” Proc. 7th Annual Working Group on Extraterrestrial Resources, NASA SP-229 (1970) pp. 113-115.

5. R.L. Vander Wal, et al., manuscript submitted for publication (2009).

6. W.T. Wallace, D.K. Hammond, and A.S. Jeevarajan, "Lunar Dust and Lunar Simulant Activation and Monitoring," NASA Human Research Program Investigators" Workshop, League City, TX (2008).

7. H.P. Hoyt, Jr., et al., "Solar Flare Proton Spectrum Averaged Over the Last $5 \times 10^{3}$ Years," Proc. Fourth Lunar Science Conf., vol. 3, (1973) pp. 2489-2502.

8. J.J. Grossman, et al., "Microchemical, microphysical and adhesive properties of lunar material,” Proc Apollo 11 Lunar Sci Conf., vol. 3, pp. 2171-2181.

9. Carl Allen, at the Biological Effects of Lunar Dust Workshop, March 29-31, 2005.

10. P. Atkins, Physical Chemistry, 6th ed. (W.H. Freeman and Co., New York, 1999) p. 29.

11. F. Mota, et al., "Radiation Damage Modeling of Fused Silica in Fusion Systems,” IAEA2006, paper ITERP1-30 (2006).

12. J.R. Gaier and E.A. Sechkar, "Lunar Simulation in the Lunar dust Adhesion Bell Jar,” NASA/TM-2007-214704, 2007.

13. K.W. Street, Jr., NASA Glenn Research Center, private communications (2008).

14. CRC Handbook of Chemistry and Physics, 76th Ed. (1995), D.R. Lide, Ed., pp. 9-51-9-74.

15. 2000 ASTM Standard Extraterrestrial Spectrum Reference E-490-00, at http://rredc.nrel.gov/solar/ spectra/am0/, accessed Feb. 26, 2009.

16. Z. Sternovsky, et al., "Contact charging of lunar and Martian dust simulants,” J. Geophy Res 107 (E11) (2002) pp. 15-1-15-8.

17. J.W. Wilson et al., "Transport Methods and Interactions for Space Radiations,” NASA Reference Publication 1257 (1991).

18. G.H. Heiken, D.T. Vaniman, and B.M. French, The Lunar Sourcebook: A User's Guide to the Moon, (Cambridge University Press, 1991), p. 444.

19. E.L. Christiansen, "Meteoroid/Debris Shielding,” NASA/TP—2003210788. 


\begin{tabular}{|c|c|c|}
\hline \multicolumn{2}{|c|}{ REPORT DOCUMENTATION PAGE } & $\begin{array}{l}\text { Form Approved } \\
\text { OMB No. 0704-0188 }\end{array}$ \\
\hline \multicolumn{3}{|c|}{$\begin{array}{l}\text { The public reporting burden for this collection of information is estimated to average } 1 \text { hour per response, including the time for reviewing instructions, searching existing data sources, gathering and maintaining the } \\
\text { data needed, and completing and reviewing the collection of information. Send comments regarding this burden estimate or any other aspect of this collection of information, includiding suggestions for reducting this } \\
\text { burden, to Department of Defense, Washington Headquarters Services, Directorate for Information Operations and Reports (0704-0188), } 1215 \text { Jefferson Davis Highway, Suite } 1204 \text {, Arlington, VA } 22202-4302 \text {. } \\
\text { Respondents should be aware that notwithstanding any other provision of law, no person shall be subject to any penalty for failing to comply with a collection of information if it does not display a currently valid OMB } \\
\text { control number. } \\
\text { PLEASE DO NOT RETURN YOUR FORM TO THE ABOVE ADDRESS. }\end{array}$} \\
\hline $\begin{array}{l}\text { 1. REPORT DATE (DD-MM-YYYY) } \\
01-10-2009\end{array}$ & $\begin{array}{l}\text { 2. REPORT TYPE } \\
\text { Technical Memorandum }\end{array}$ & 3. DATES COVERED (From - To) \\
\hline \multirow{3}{*}{\multicolumn{2}{|c|}{$\begin{array}{l}\text { 4. TITLE AND SUBTITLE } \\
\text { Regolith Activation on the Lunar Surface and Its Ground Test Simu }\end{array}$}} & 5a. CONTRACT NUMBER \\
\hline & & 5b. GRANT NUMBER \\
\hline & & 5c. PROGRAM ELEMENT NUMBER \\
\hline \multirow{3}{*}{\multicolumn{2}{|c|}{$\begin{array}{l}\text { 6. AUTHOR(S) } \\
\text { Gaier, James, R. }\end{array}$}} & 5d. PROJECT NUMBER \\
\hline & & 5e. TASK NUMBER \\
\hline & & $\begin{array}{l}\text { 5f. WORK UNIT NUMBER } \\
\text { WBS 936374.04.08.03 }\end{array}$ \\
\hline \multicolumn{2}{|c|}{$\begin{array}{l}\text { 7. PERFORMING ORGANIZATION NAME(S) AND ADDRESS(ES) } \\
\text { National Aeronautics and Space Administration } \\
\text { John H. Glenn Research Center at Lewis Field } \\
\text { Cleveland, Ohio 44135-3191 }\end{array}$} & $\begin{array}{l}\text { 8. PERFORMING ORGANIZATION } \\
\text { REPORT NUMBER } \\
\text { E-16960 }\end{array}$ \\
\hline \multirow{2}{*}{\multicolumn{2}{|c|}{$\begin{array}{l}\text { 9. SPONSORING/MONITORING AGENCY NAME(S) AND ADDRESS(ES) } \\
\text { National Aeronautics and Space Administration } \\
\text { Washington, DC 20546-0001 }\end{array}$}} & $\begin{array}{l}\text { 10. SPONSORING/MONITOR'S } \\
\text { ACRONYM(S) } \\
\text { NASA }\end{array}$ \\
\hline & & $\begin{array}{l}\text { 11. SPONSORING/MONITORING } \\
\text { REPORT NUMBER } \\
\text { NASA/TM-2009-215648 }\end{array}$ \\
\hline \multicolumn{3}{|c|}{$\begin{array}{l}\text { 12. DISTRIBUTION/AVAILABILITY STATEMENT } \\
\text { Unclassified-Unlimited } \\
\text { Subject Category: } 91 \\
\text { Available electronically at http://gltrs.grc.nasa.gov } \\
\text { This publication is available from the NASA Center for AeroSpace Information, 443-757-5802 }\end{array}$} \\
\hline
\end{tabular}

\section{SUPPLEMENTARY NOTES}

\section{ABSTRACT}

Activation of the surfaces of lunar regolith particles can occur through interactions with solar electromagnetic radiation, solar and galactic particle radiation and micrometeoroid bombardment. An attempt has been made to quantify the relative importance of each of those effects. The effects of these activated surfaces may be to enhance the adhesion and toxicity of the particles. Also key to the importance of activation is the lifetimes of activated states in various environments which is controlled by their passivation rate as well as their activation rate. Although techniques exist to characterize the extent of activation of particles in biological system, it is important to be able to quantify the activation state on the lunar surface, in ground-test vacuum systems, and in habitat atmospheres as well.

\section{SUBJECT TERMS}

Lunar soil; Lunar dust

\begin{tabular}{|c|c|c|c|c|c|}
\hline \multicolumn{3}{|c|}{ 16. SECURITY CLASSIFICATION OF: } & \multirow{2}{*}{$\begin{array}{l}\text { 17. LIMITATION OF } \\
\text { ABSTRACT } \\
\text { UU }\end{array}$} & \multirow{2}{*}{$\begin{array}{l}\text { 18. NUMBER } \\
\text { OF } \\
\text { PAGES } \\
12\end{array}$} & \multirow{2}{*}{$\begin{array}{l}\text { 19a. NAME OF RESPONSIBLE PERSON } \\
\text { STI Help Desk (email:help@sti.nasa.gov) } \\
\text { 19b. TELEPHONE NUMBER (include area code) } \\
\text { 443-757-5802 }\end{array}$} \\
\hline $\begin{array}{l}\text { a. REPORT } \\
U\end{array}$ & $\begin{array}{l}\text { b. ABSTRACT } \\
\mathrm{U}\end{array}$ & $\begin{array}{l}\text { c. THIS } \\
\text { PAGE } \\
\text { U }\end{array}$ & & & \\
\hline
\end{tabular}



